\title{
A Case of Oculomotor Nerve Paralysis Caused by Cavernous Sinus Metastasis of Tonsil Cancer
}

\author{
Younghac Kim, MD, Man Ki Chung, MD, PhD, and Sang Duk Hong, MD, PhD \\ Department of Otorhinolaryngology-Head and Neck Surgery, Samsung Medical Center, School of Medicine, Sungkyunkwan University, \\ Seoul, Republic of Korea
}

\begin{abstract}
Oropharyngeal squamous cell carcinoma (OSCC) with metastasis to the cavernous sinus (CS) is uncommon, and only a few cases have been described in the literature. The highest age-adjusted incidence rate for OSCC including the tonsil in males occurs in South Asians, and more cases should be reported to establish earlier identification and treatment. We report a case of OSCC in a 59-year-old male who underwent prompt endoscopic biopsy and early palliative radiation therapy to allow complete recovery of cranial nerve palsies to improve his quality of life, despite having a poor prognosis. Furthermore, this report emphasizes his dramatic resolution of symptoms after radiation therapy, highlighting the importance of rapid recognition and proper management.
\end{abstract}

Keywords: Tonsil cancer; Oropharyngeal squamous cell carcinoma; Cavernous sinus; Oculomotor nerve paralysis.

\section{INTRODUCTION}

The incidence of tonsil cancer has been increasing, which can be attributed to a growing proportion of diagnoses associated with infection by the human papillomavirus (HPV) [1]. Because HPV-positive oropharyngeal squamous cell carcino$\mathrm{ma}$ (OSCC) is more responsive to chemoradiotherapy than HPV-negative OSCC [2]. Cases of HPV-positive OSCC are associated with more favorable outcomes than those occurring in the absence of HPV infection [3].

Fifteen to twenty percent of oropharyngeal carcinomas develop distant metastases that most commonly involve the lung, liver and bone, and some retrospective reviews have reported that metastases with HPV-related disease are more likely to include unusual sites [4]. As the cavernous sinus involves cranial nerves III to VI, patients with cavernous sinus metastasis could demonstrate symptoms of acute onset diplopia, ptosis and paralytic strabismus.

Received: July 18, 2021 Revised: August 19, 2021

Accepted: August 27, 2021

Address for correspondence: Sang Duk Hong, MD, PhD, Department of Otorhinolaryngology-Head and Neck Surgery, Samsung Medical Center, School of Medicine, Sungkyunkwan University, 81 Irwon-ro, Gangnam-gu, Seoul 06351, Republic of Korea

Tel: +82-2-3410-3579, Fax: +82-2-3410-1785, E-mail: kkam97@gmail.com This is an Open Access article distributed under the terms of the Creative Commons Attribution Non-Commercial License (https://creativecommons.org/licenses/bync/4.0) which permits unrestricted non-commercial use, distribution, and reproduction in any medium, provided the original work is properly cited.
Few authors have previously reported metastasis to the cavernous sinus from head and neck cancer, and especially, few Asian cases have been reported. We present a patient with diplopia, ptosis and paralytic strabismus caused by a cavernous sinus metastasis who was previously diagnosed with HPVpositive OSCC.

\section{CASE REPORT}

A 59-year-old male ex-smoker (30 PY) who had a six-month history of an enlarging right neck mass associated with neck pain and dysphagia was referred to the head and neck surgery clinic. He was diagnosed with HPV-positive squamous cell carcinoma with neck metastasis (T1N1M0) after biopsy and imaging studies including magnetic resonance imaging (MRI) (Fig. 1). He underwent right palatine tonsillectomy and right modified neck dissection.

After surgery, his pathological staging was modified to pT2N1 (American Joint Committee on Cancer [AJCC] 8th) with extranodal extension to the right $2 \mathrm{~A}$ lymph nodes and with a close resection margin. The patient received adjuvant $5,940 \mathrm{cGy}$ in 27 fractions to the primary site and ipsilateral neck. Adjuvant concurrent chemotherapy consisted of intravenous cisplatin given as a loading dose of $164 \mathrm{mg} / \mathrm{m}^{2}$, which was started on the first day of radiotherapy, but only one more identical dose of cisplatin was given because the patient was reluctant about continuing chemotherapy. 
Five months after completing the surgery and adjuvant chemoradiotherapy, the patient visited the emergent department because of complete ptosis and paralytic strabismus of

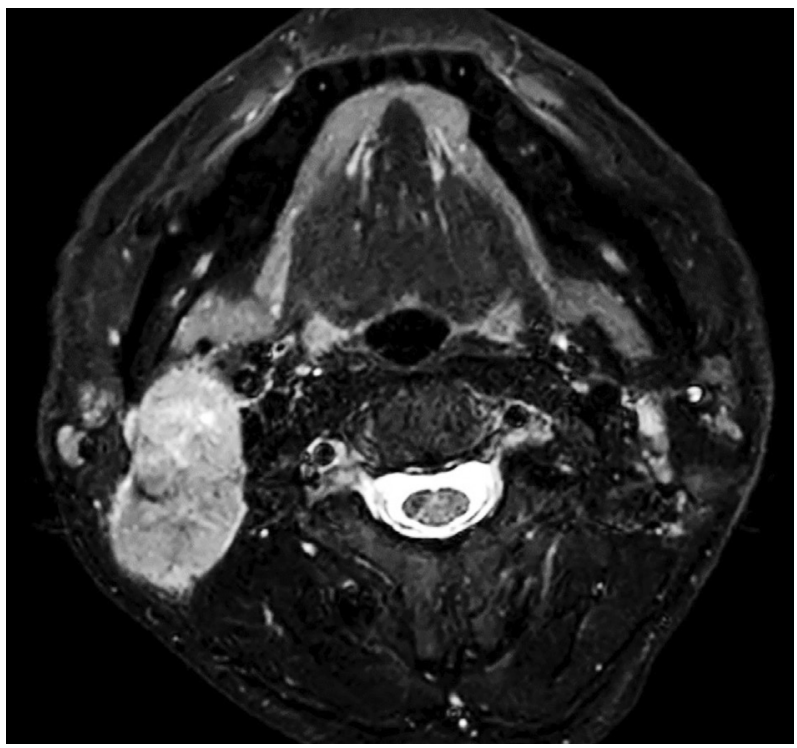

Fig. 1. Preoperative radiologic image of the patient. Axial contrastenhanced magnetic resonance imaging scan shows a $1.2 \mathrm{~cm}$-sized right palatine tonsil mass with large ipsilateral cervical lymph node metastasis. the right eye (Fig. 2). Physical examination revealed right-sided cranial nerve III and VI palsy. MRI showed a mass-like lesion in the right cavernous sinus (Fig. 3A). Because cavernous metastasis from tonsil cancer rarely occurs, we prescribed a total of 12 administrations of high dose intravenous methylprednisolone $250 \mathrm{mg} 4$ times per day with 3 days to rule out neuritis or Tolosa Hunt syndrome. After steroid therapy, however, the ptosis and diplopia did not resolve, so we decided to perform an endoscopic biopsy for the cavernous sinus lesion. After ethmoidectomy and large sphenoidotomy, we performed the biopsy under image guidance (Fig. 3B). Results from the biopsy confirmed metastasis of HPV-positive squamous cell carcinoma (Fig. 4). The patient received an additional 6,000 cGy in 20 fractions to the right cavernous sinus, and the patient's ptosis and diplopia improved within one month (Fig. 5). He is planned to have regular follow-ups in the otolaryngology, and radiology departments, and his recent 12 months follow up of neck CT scan showed no evidence of recurrence.

\section{DISCUSSION}

This case is unusual; he had HPV-positive tonsil cancer that metastasized to the cavernous sinus without any other distant
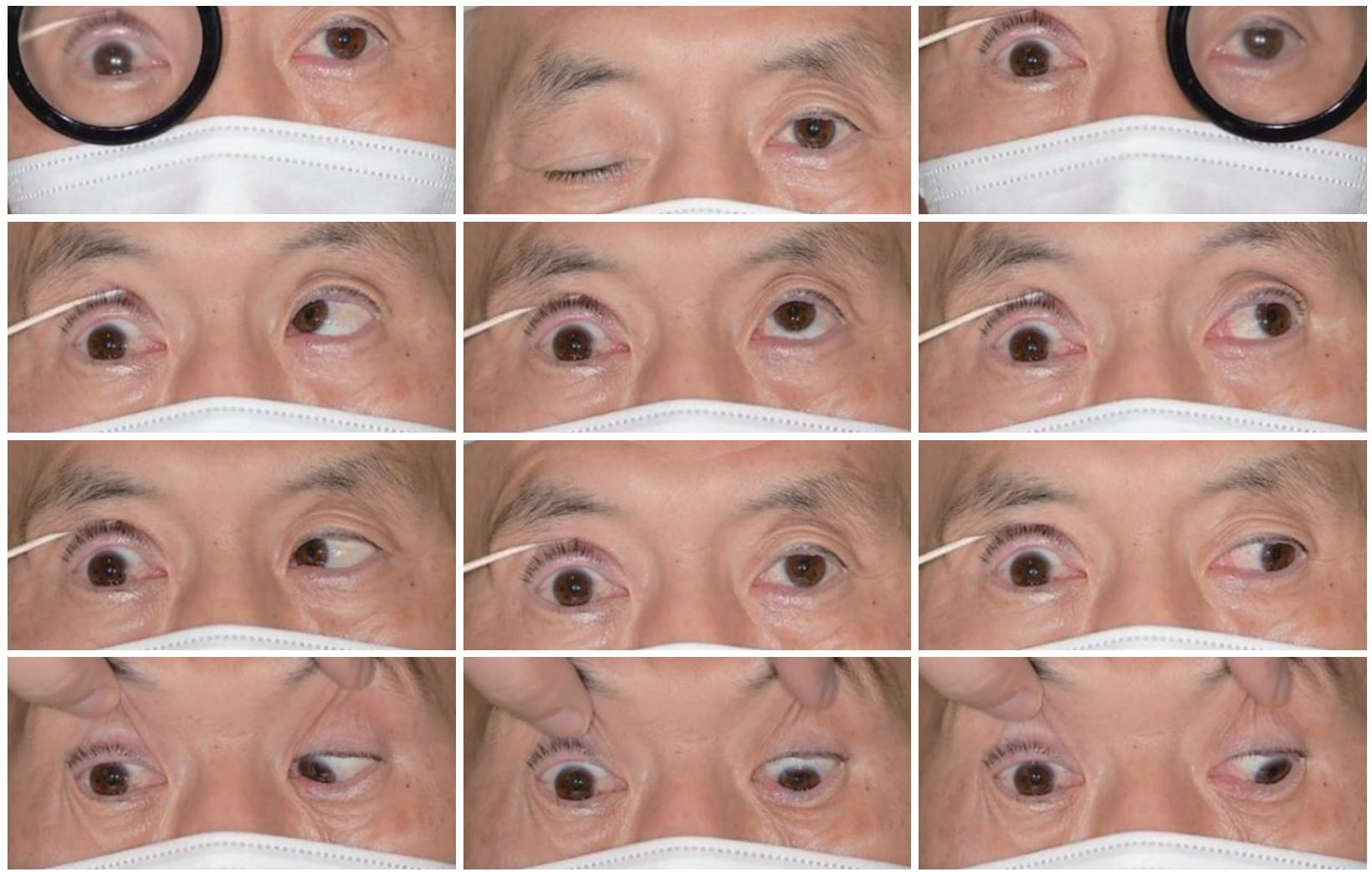

Fig. 2. Photograph of the eye examination. A 9-gaze photo demonstrates the patient's complete ptosis and limitation of extraocular muscle movement. 

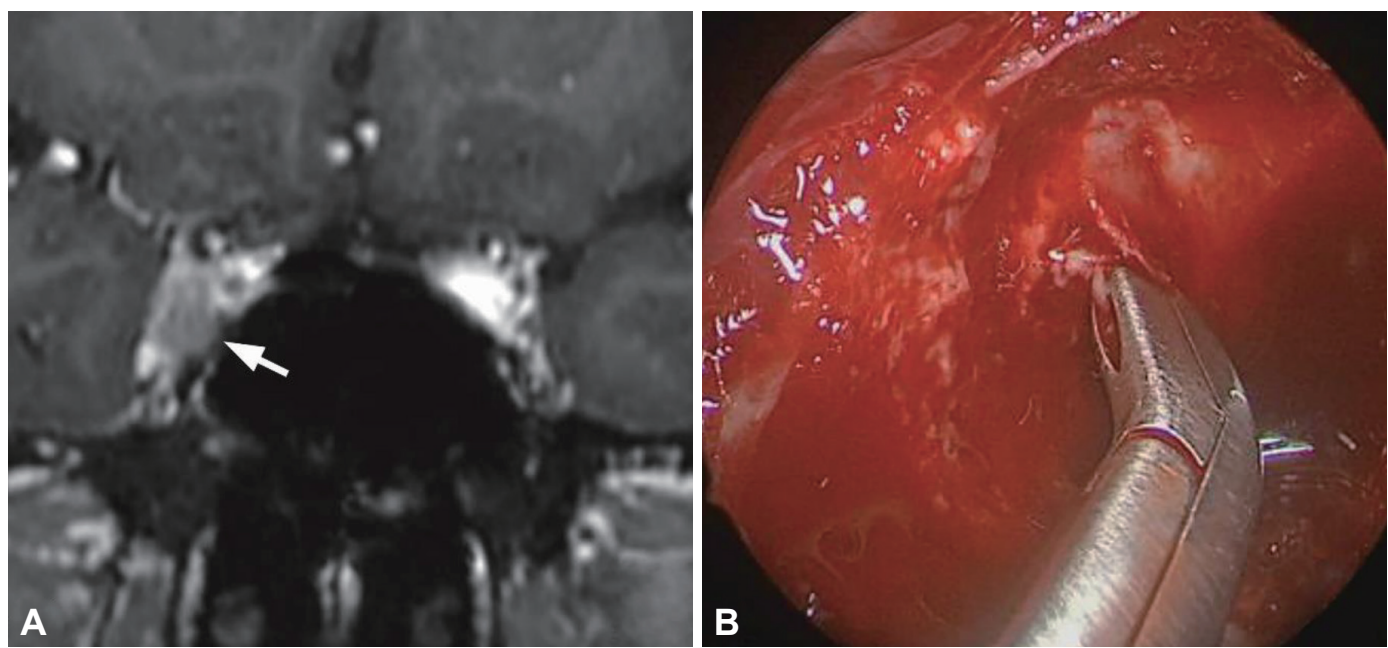

Fig. 3. Radiologic, intraoperative image of cavernous sinus lesion. A: Coronal gadolinium-enhanced magnetic resonance imaging shows a mass-like lesion (arrow) in the cavernous sinus. B: Intraoperative view; after the cavernous medial dura was incised, a biopsy was performed.
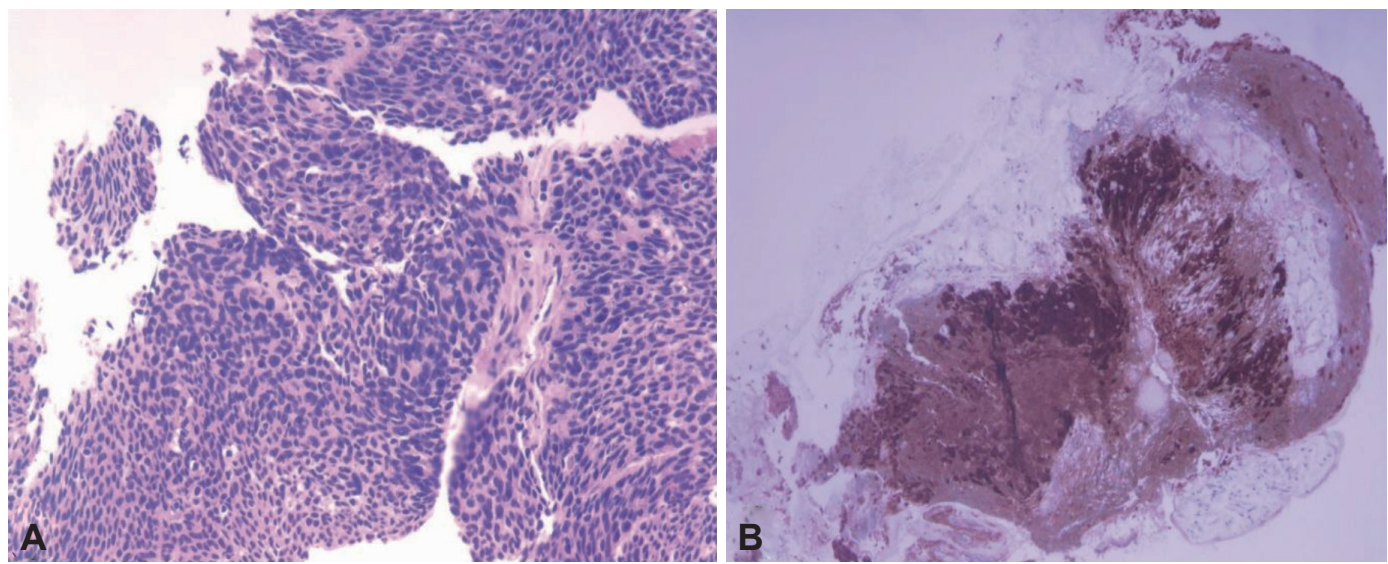

Fig. 4. Pathologic findings of the mass. Hematoxylin and eosin $(H \& E)$ stain $(\times 100)(A)$ and $P 16$ stain $(\times 40)(B)$ shows tumor consists of non-keratinizing P16 stain positive metastatic squamous cell carcinoma.
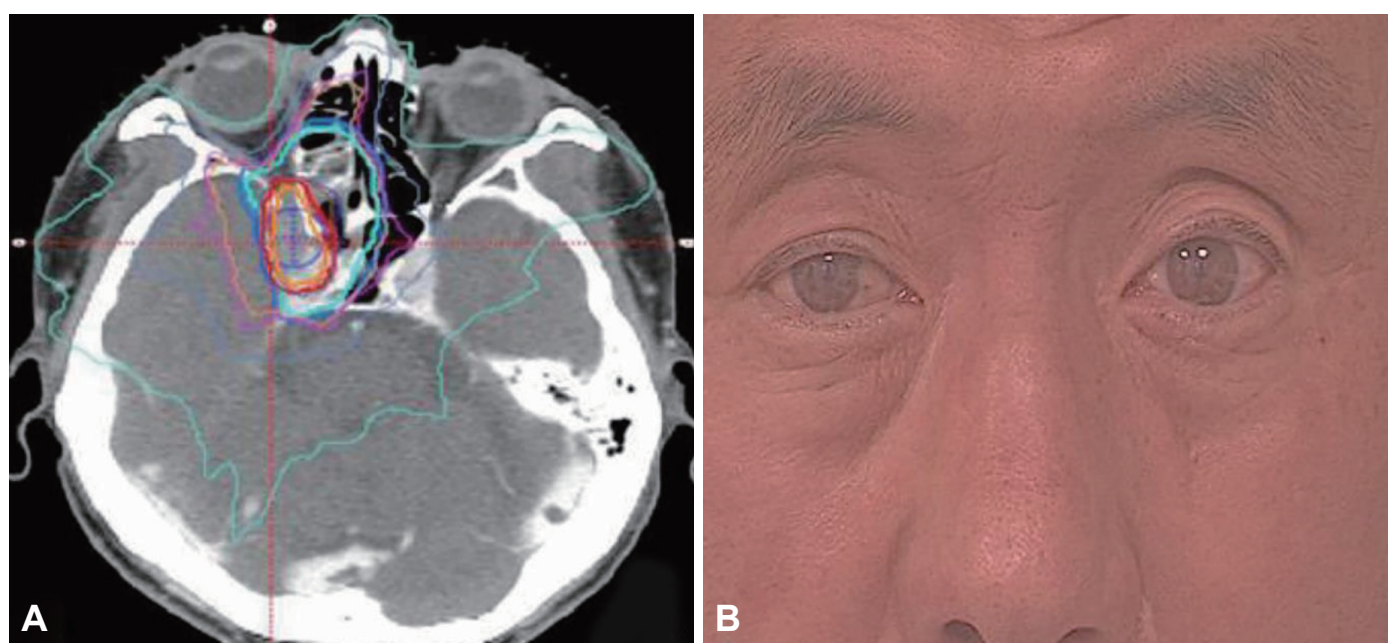

Fig. 5. Dose distribution of adjuvant radiotherapy and postoperative eye photograph. (A) The patient received an additional 6,000 cGy in 20 fractions to the right cavernous sinus, (B) and the ptosis improved within one month. 
metastases to the common locations. Very few cases of OSCC metastasis to the cavernous sinus have been reported in the English literature [5-7]. Physicians must maintain a high index of suspicion in patients with a history of malignancy who present with symptoms involving the cavernous sinus. In this situation, detailed physical examinations and imaging studies to investigate a potential etiology must be performed. If imaging studies, such as MRI, reveal the possibility of a cavernous metastasis, endoscopic biopsy could be performed [8].

When the lesion is situated medial to the internal carotid artery, an endoscopic endonasal approach would be simple and safe. However, if the lesion is lateral to the internal carotid artery, an endoscopic transorbital approach could be another surgical option [9]. Because aggressive manipulation could cause permanent nerve paralysis, sharp dissection and small multiple biopsies are suggested when performing the biopsy [10].

Although the exact mechanisms or pathways to the cavernous sinus from the oropharynx have not been revealed, hematogenous metastasis is the most reliable theory because of the high vascularity of the cavernous sinus. Therefore, the overall prognosis is likely to be poor; the expected mortality is $75 \%$ to $85 \%$ within two years [11].

Despite the patient's overall poor prognosis, physicians must confirm whether the lesion is a metastasis or a primary tumor. In our case, we promptly performed an endoscopic biopsy, and the patient received early palliative radiation therapy, which allowed complete recovery of the cranial nerve palsies and improved the quality of life for our patient with a poor prognosis.

In conclusion, cavernous sinus metastasis from oropharyngeal carcinoma must be considered in cases of cranial nerve palsies involving the cavernous sinus. Prompt endoscopic biopsy will provide accurate information about prognosis, and proper treatment, such as adjuvant radiation therapy, could improve the quality of life.

\section{Ethics Statement}

Written informed consent for image use was obtained from the patient.

\section{Availability of Data and Material}

The datasets generated or analyzed during the study are available from the corresponding author on reasonable request.

\section{Conflicts of Interest}

The authors have no potential conflicts of interest to disclose.

\section{Author Contributions}

Conceptualization: Younghac Kim, Sang Duk Hong. Data curation: Younghac Kim. Methodology: Sang Duk Hong. Supervision: Sang Duk Hong, Man Ki Chung. Writing_-original draft: Younghac Kim. Writing_review \& editing: Sang Duk Hong, Man Ki Chung.

\section{ORCID iDs}

$\begin{array}{ll}\text { Younghac Kim } & \text { https://orcid.org/0000-0002-3276-1408 } \\ \text { Man Ki Chung } & \text { https://orcid.org/0000-0002-1435-7786 } \\ \text { Sang Duk Hong } & \text { https://orcid.org/0000-0003-3075-1035 }\end{array}$

Funding Statement

None

\section{REFERENCES}

1. Johnson-Obaseki S, McDonald JT, Corsten M, Rourke R. Head and neck cancer in Canada: trends 1992 to 2007. Otolaryngol Head Neck Surg 2012;147(1):74-8.

2. Ang KK, Harris J, Wheeler R, Weber R, Rosenthal DI, Nguyen-Tân PF, et al. Human papillomavirus and survival of patients with oropharyngeal cancer. N Engl J Med 2010;363(1):24-35.

3. Glastonbury CM. Head and neck squamous cell cancer: approach to staging and surveillance. In: Hodler J, Kubik-Huch RA, von Schulthess GK, editors. Diseases of the brain, head and neck, spine 2020-2023: diagnostic Imaging. 1st ed. Cham (CH): Springer International Publishing; 2020. p.215-22.

4. Huang SH, Perez-Ordonez B, Liu FF, Waldron J, Ringash J, Irish J, et al. Atypical clinical behavior of p16-confirmed HPV-related oropharyngeal squamous cell carcinoma treated with radical radiotherapy. Int J Radiat Oncol Biol Phys 2012;82(1):276-83.

5. Marchese-Ragona R, Maria Ferraro S, Marioni G, Staffieri C, Manara R, Restivo DA, et al. Abducent nerve paralysis: first clinical sign of clivus metastasis from tonsillar carcinoma. Acta Otolaryngol 2008;128(6): 713-6.

6. González García R, Sastre Pérez J, Naval Gías L, Rodríguez Campo FJ, Díaz González FJ. Cavernous sinus metastasis from oropharyngeal squamous cell carcinoma. Med Oral Patol Oral Cir Bucal 2007;12(2): E166-70.

7. Forner D, Wilke D, Rigby MH, Croul S, Mishra A, Massoud E, et al. Cavernous sinus involvement in human papillomavirus associated oropharyngeal squamous cell carcinoma: case report of an atypical site of distant metastasis. J Otolaryngol Head Neck Surg 2018;47(1):32.

8. Dellaretti M, Almeida JC, Martins WCDS, Faria MP. Percutaneous biopsy of lesions in the cavernous sinus: a systematic review. World Neurosurg 2017;108:1-5.

9. Bly RA, Ramakrishna R, Ferreira M, Moe KS. Lateral transorbital neuroendoscopic approach to the lateral cavernous sinus. J Neurol Surg B Skull Base 2014;75(1):11-7.

10. Liu HS, Di X. Endoscopic endonasal surgery for biopsy of cavernous sinus lesions. Minim Invasive Neurosurg 2009;52(2):69-73.

11. Rosenfeld DJ, Berenholz L, Glasgold M, Rao V, Spiegel J. Malignant neoplasms of the sphenoid sinus. Trans Pa Acad Ophthalmol Otolaryngol 1987;39(1):618-21. 